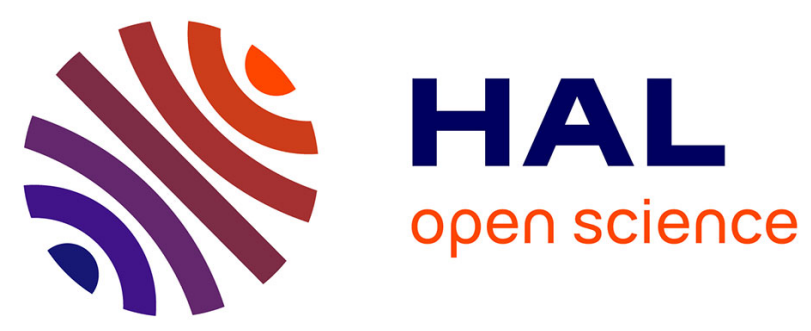

\title{
Upgrade of a petrochemical wastewater treatment plant by an upflow anaerobic pond
}

\author{
Adalberto Noyola, Hervé Macarie, Fernando Varela, Stéphanie Landrieu, \\ Roberto Marcelo, Miguel A. Rosas
}

\section{- To cite this version:}

Adalberto Noyola, Hervé Macarie, Fernando Varela, Stéphanie Landrieu, Roberto Marcelo, et al.. Upgrade of a petrochemical wastewater treatment plant by an upflow anaerobic pond. Water Science and Technology, 2000, 42 (5-6), pp.269-276. 10.2166/wst.2000.0523 . hal-01761201v2

\section{HAL Id: hal-01761201 \\ https://hal.science/hal-01761201v2}

Submitted on 5 Apr 2019

HAL is a multi-disciplinary open access archive for the deposit and dissemination of scientific research documents, whether they are published or not. The documents may come from teaching and research institutions in France or abroad, or from public or private research centers.
L'archive ouverte pluridisciplinaire HAL, est destinée au dépôt et à la diffusion de documents scientifiques de niveau recherche, publiés ou non, émanant des établissements d'enseignement et de recherche français ou étrangers, des laboratoires publics ou privés. 


\title{
UPGRADE OF A PETROCHEMICAL WASTEWATER TREATMENT PLANT BY AN UPFLOW ANAEROBIC POND
}

\author{
Adalberto Noyola*1, Hervé Macarie**, Fernando Varela***, \\ Stéphanie Landrieu**, Roberto Marcelo*** and Miguel Angel Rosas**** \\ * Instituto de Ingeniería UNAM, A. P. 70-473. Cd. Universitaria, 04510 México D.F., México \\ ** Institut de Recherche pour le Développement (IRD-France), Cicerón 609, Col. Los Morales, \\ 11530 México D.F., México and Universidad Autónoma Metropolitana-Iztapalapa, México D.F. \\ *** Tereftalatos Mexicanos S. A., A. P. 204, 96700 Minatitlán, Ver., México \\ **** IBtech S. A. de C. V., Pasadena 18, Col. Del Valle, 03100 México D.F., México \\ ${ }^{1}$ Corresponding author.Email: noyola@pumas.iingen.unam.mx
}

\begin{abstract}
A petrochemical plant producing terephthalic acid faced a saturation of its wastewater treatment facilities due to an increase in production. In fact, the plant has been growing in the last years, and the effluents have been treated by reproducing the original activated sludge design. However, due to lack of space, as well as energy consumption and sludge production reaching a certain level, the plant considered other options for coping with the new effluent flow and organic load.

Based on the authors' previous experience with this wastewater, the consultant designed a process consisting in modifying an existing pond, in order to add an anaerobic step previous to the aerobic tanks already in operation. The anaerobic pond is a three stage process, all included in the same adapted basin, with a distribution system in the bottom of each stage that creates an upflow pattern. Terephthalic acid wastewater is a mixture of several organic acids, with different anaerobic degradation kinetics, acetic and benzoic acids being more rapidly removed; the staged design takes this into account. The first two stages have a plastic floating cover $\left(5,813 \mathrm{~m}^{3}\right.$ and $8,719 \mathrm{~m}^{3}$ volume, respectively), while the third one is a conventional UASB type reactor $\left(6,276 \mathrm{~m}^{3}\right.$ volume $)$ with a gas-liquid-solid separation device on top.

The design wastewater flow is $230 \mathrm{~m}^{3} / \mathrm{h}$, with $10,300 \mathrm{mg} / \mathrm{COD}$, a $\mathrm{pH}$ of 4.5 and a temperature of $40^{\circ} \mathrm{C}$. There is an effluent recycling pump $\left(510 \mathrm{~m}^{3} / \mathrm{h}\right)$ in order to control upflow velocities and eventual acidification problems in the first two stages. The reactor, seeded with anaerobically adapted waste sludge from the aerobic plant, is now under start up, with the expected performance.
\end{abstract}

\section{KEYWORDS}

Anaerobic pond, anaerobic treatment, benzoic acid, PTA, terephthalic acid, p-toluic acid.

\section{INTRODUCTION}

Tereftalatos Mexicanos S. A. (Temex) is dedicated to the manufacture of purified terephthalic acid $(1,4-$ benzenedicarboxylic acid) or PTA which is used, together with ethylene glycol, as raw material for the production of polyester fibers, films and molding resins. Presently, Temex has an installed capacity of 950,000 PTA tons/year in two industrial sites, one (600,000 tons/year) being located at Cosoleacaque in the south of Veracruz state. With such capacity, Tereftalatos Mexicanos is now one of the 5 biggest PTA producers in the world.

Temex started its activities in 1978 on the site of Cosoleaque with an installed capacity of 135,000 PTA tons/year. The production plant was the result of a technological package sold by Amoco Co. It included a 
wastewater treatment plant based on an activated sludge process specially developed by Amoco for PTA wastewaters (Lau, 1978). The process consisted in 3 aeration basins in series, aeration being provided through floating, low speed surface aerators. This treatment scheme performed well until the late 80's.

The treatment capacity had however to be extended twice in order to follow the factory PTA production expansion starting in 1989. The first extension consisted in a second train of treatment identical to the previous one, both in volume and concept. The second extension resulted in the construction of 2 new basins operated in parallel and aerated with submerged diffusers in order to improve oxygen transfer and reduce electricity consumption. Despite these 2 extensions, the still growing demand for polyesters in Mexico and the rest of the world resulted in a new increase of PTA production at Cosoleacaque and so the need for a third adjustment of the wastewater treatment facility.

However, at this time, the factory was faced to a shortage of space for the reproduction of the previous aerobic options as well as for the disposal of excess activated sludge. Temex was then looking for an option, which would require less surface, would produce less solid waste and if possible, would present lower operation and maintenance costs. Other constraint was the necessity to maintain investment at the minimum possible. With these objectives, the company decided to convert an existing, unused $21,000 \mathrm{~m}^{3}$ basin into an anaerobic reactor. This decision was motivated by Temex own experience on PTA wastewater anaerobic treatment obtained over the last 10 years during laboratory and pilot scale experiments performed with the collaboration of three research institutions (Guyot et al., 1990; Noyola et al., 1990; Macarie et al., 1992; Varela et al., 1998). The decision was also greatly influenced by the fact that since 1989, Amoco Co., the world leader PTA producer, confirmed at full scale, in most of its production facilities, the feasibility and economical advantages of anaerobic treatment of PTA wastewater (Shelley, 1991), an example already followed by several other important PTA producers (Pereboom et al., 1994; Page et al., 1998; Macarie, 2000).

The objectives of this paper are to present (1) the design selected for the anaerobic reactor together with the microbiological and technical reasons behind it, (2) its inoculation and (3) the first results of operation obtained during the start-up of the plant.

\section{BACKGROUND}

\section{Wastewater composition}

The wastewater at Cosoleacaque is typical of that generated during the manufacture of PTA using the pxylene oxidation process commercialized by Amoco Co. (Cheng et al., 1997; Fajardo et al., 1997; Kleerebezem et al., 1997; Young, 1997). More precisely, it is produced at a flow rate of $3-4 \mathrm{~m}^{3} / \mathrm{PTA}$ ton, has a $\mathrm{pH}$ of $4.5(3-5)$, a temperature of $56^{\circ} \mathrm{C}\left(50-60^{\circ} \mathrm{C}\right)$ and contains 4,000 to $12,000 \mathrm{mg} \mathrm{COD} / \mathrm{L}$ mainly as aromatic compounds and acetic acid (AA, 30-1,180 mg/L), 30\% being particulate COD. The aromatic organics correspond to terephthalic acid (TA, 1,240-3,900 mg/L) and by-products formed during its synthesis: benzoic acid (benzenecarboxylic acid, BA, 103-3,800 mg/L), p-toluic acid (4-methylbenzoic acid, p-tol, 138-1,749 mg/L) as well as lower amounts of phthalic acid (1,2-benzenedicarboxylic acid, PA, 70 $\mathrm{mg} / \mathrm{L}$ ), isophthalic acid (1.3-benzenedicarboxylic acid, IA, 190-690 mg/L), trimellitic acid (1,2,4benzenetricarboxylic acid, TMA, $140 \mathrm{mg} / \mathrm{L}$ ) and 4-carboxybenzaldehyde (4-CBA, 2-180 mg/L).

All these aromatic compounds are almost completely dissolved at the concentrations and $\mathrm{pH}$ of the raw wastewater except TA which is, in these conditions, in its protonated form, poorly soluble in water (solubility: $19 \mathrm{mg} / \mathrm{L}$ at $25^{\circ} \mathrm{C}$ and $400 \mathrm{mg} / \mathrm{L}$ at $100^{\circ} \mathrm{C}$ after Bemis et al., 1982). As a consequence, TA makes most of the 1-3 g/L of the suspended solids present in the effluent. Since 1993, in addition, a small fraction $(5 \%)$ of Cosoleacaque COD comes from an Eastman facility that produces PET (polyethylene terephthalate). 
Most of this COD load corresponds to ethylene glycol, which is present in the final wastewater at a concentration of about $200 \mathrm{mg} / \mathrm{L}$. The wastewater contains also some of the catalysts (Co, Mn), and the chemical promoter $(\mathrm{Br})$ used during the production process, as well as corrosion metals $(\mathrm{Fe}, \mathrm{Cr}, \mathrm{Ni}$, etc) from pipes, vessels and general equipment. It is however devoid of nitrogen and phosphorous.

\section{Wastewater anaerobic biodegradability and its implication on reactor design}

Previous works have shown that most of the organic compounds present in PTA wastewater (acetic acid, phthalic acid isomers, p-toluic and benzoic acids), once neutralized, can be converted to $\mathrm{CH}_{4}$ and $\mathrm{CO}_{2}$ under mesophilic conditions $\left(35^{\circ} \mathrm{C}\right)$ ( $\mathrm{Li}$ et al., 1995; Macarie and Guyot, 1995; Kleerebezem et al., 1999a). Regarding the kinetic of their methanization, these compounds can be divided in two groups. In fact, while acetate and benzoate are degraded at high rates (0.6-1 g COD/g VSS.d) (Pereboom et al., 1994; Li et al., 1995), phthalate isomers and p-toluate can be only degraded at low rates $(<0.1 \mathrm{~g} \mathrm{COD} / \mathrm{g}$ VSS.d), at least when mixed with the other compounds (Kleerebezem et al., 1997). Individually the situation can be different, and for instance, high rates have been obtained with terephthalate when present as sole carbon and energy source (Kleerebezem et al., 1999c). Besides their fast degradation kinetics, benzoate and acetate have been shown also to inhibit the degradation of terephthalate and p-toluate (Macarie and Guyot, 1992; Kleerebezem et $a l, 1999 \mathrm{~b})$. This inhibition is irreversible in the case of acetate and only partially reversible in the case of benzoate (Fajardo et al., 1997; Kleerebezem et al, 1999b).

A test consisting to mix, at a ratio of $1 \mathrm{~g}$ COD $/ \mathrm{g}$ VSS, a sample of neutralized settled wastewater from Cosoleacaque and the sludge of a pilot scale UASB reactor treating the same wastewater, has confirmed that at $35^{\circ} \mathrm{C}$, the biodegradability of this effluent supplemented with nitrogen, phosphorous and sulfur at a $\mathrm{COD} / \mathrm{N} / \mathrm{P} / \mathrm{S}$ ratio of 100/2/0.4/0.2, follows the previous pattern. As shown in Figure 1, the methane production from this wastewater is biphasic. The first phase, which lasts 10 days, corresponds only to the degradation of acetate. Afterwards, 10 more days are necessary to observe a new phase of methane production, which corresponds to the degradation of TA, PA, TMA and 4-CBA. The behaviour of BA, p-tol and IA was not followed during this experiment but, based on the mentioned references, it can be assumed that BA was removed together with AA and that p-tol and IA had the same behaviour as the other aromatic compounds.

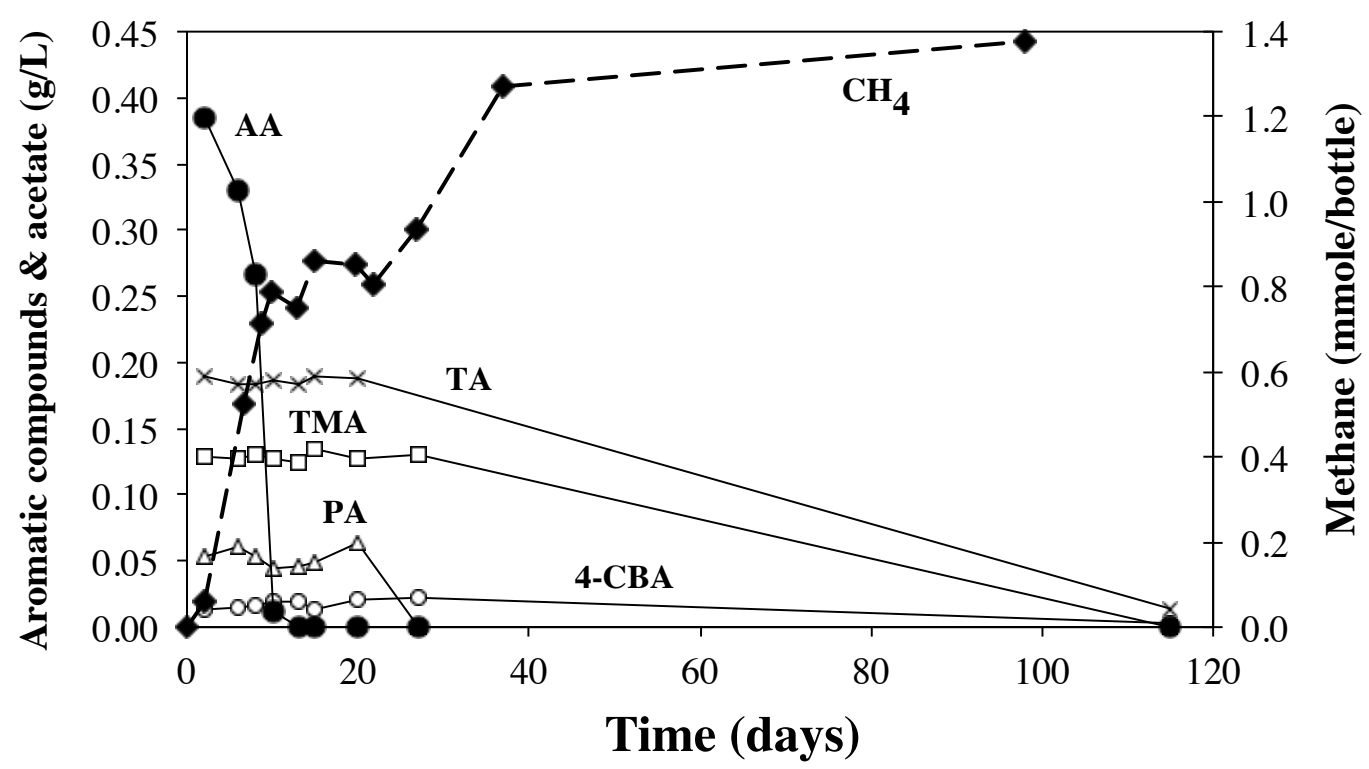

Figure 1. Batch degradation of aromatic compounds and acetate from terephthalic acid wastewater and corresponding methane production. 
These results and the literature data indicate that for this type of wastewater, the aromatic pollutants will be methanized only in the presence of very low concentrations of BA and AA. In such a case, a plug flow pattern must be favoured over a completely mixed, since it allows the formation of concentration gradients and as a consequence a stratification of different biomasses adapted to the degradation of specific compounds. Such pattern can be obtained through several completely mixed reactors in series, but also through fully packed or hybrid single stage reactors operated without recycling or with a limited recycling ratio, not enough to generate perfectly mixed conditions. Nevertheless, it must be emphasized that at low organic loads $\left(1-3 \mathrm{~kg} \mathrm{COD} / \mathrm{m}^{3} . \mathrm{d} ;<0.3 \mathrm{~g} \mathrm{COD} / \mathrm{g}\right.$ VSS.d) and large sludge retention times, partial removal (20-50\%) of TA and p-tol can be also obtained in single staged perfectly mixed reactors (Cheng et al., 1997 ; Varela et al., 1998).

\section{Suspended Solids, pH and temperature.}

As indicated previously, due to its composition, PTA wastewater has an acidic pH (4.5), unsuitable for methanogenic fermentation (6.6 to 7.8), TA being present under particulate form. The wastewater must then be neutralized and the suspended solids must be removed before the anaerobic treatment, in order to prevent deposition in lines and tanks and displacement of active biomass. TA salts $\left[\mathrm{TA}\left(\mathrm{COO}^{-}\right)_{2}\right]$ are much more soluble in water than the corresponding protonated form $\left[\mathrm{TA}(\mathrm{COOH})_{2}\right]$ (i. e. $140 \mathrm{~g} / \mathrm{L}$ or $66.6 \mathrm{mM}$ for the disodium salt against $19 \mathrm{mg} / \mathrm{L}$ or $0.11 \mathrm{mM}$ for the acid at $25^{\circ} \mathrm{C}$, Bemis et al., 1982; Merck 1999/2000 Chemical Product Catalog), so neutralization can also give an answer to the solids problem by dissolving them in the aqueous phase. However, the amount of alkaline reagent needed to neutralize the acids in solution and neutralize/dissolve TA, is very high, with an important impact on the influent organic load, as well as at the level of operation cost. In practice, the amount of neutralizing agent can be reduced separating the TA solids from the wastewater by settling, taking advantage of its high density $\left(1.5 \mathrm{~kg} / \mathrm{L}\right.$ at $25^{\circ} \mathrm{C}$ after Bemis et al., 1982). Such settling is already performed at Cosoleacaque in a pond which was in fact originally designed to reduce the wastewater temperature below $40^{\circ} \mathrm{C}$ before the aeration tanks. This requirement has been kept for the anaerobic step.

Even in the absence of TA suspended solids, the amount of alkaline compounds to neutralize the soluble acids remains high for the raw wastewater. However, the methanogenic fermentation of these molecules corresponds to the conversion of fairly strong acids [pKa at $25^{\circ} \mathrm{C}$ of AA (4.76), BA (4.2), p-tol (4.36), TA (3.54; 4.46) PA (2.95; 5.41), IA (3.62; 4.6), TMA $(2.52 ; 3.84 ; 5.2)$, Dean, 1992] into $\mathrm{CO}_{2}$ which is a much weaker one $\left(\mathrm{pKa} \mathrm{CO}_{2} / \mathrm{HCO}_{3}{ }^{-}=6.4\right.$ at $\left.25^{\circ} \mathrm{C}\right)$. This means that the methanogenic fermentation of these compounds will generate alkalinity and that a neutral $\mathrm{pH}$ can be maintained in the reactor even if fed with an acidic wastewater as shown previously in the case of fatty acid mixtures (Koster, 1986). A pilot scale experiment performed at Cosoleacaque during 4 months with a $1 \mathrm{~m}^{3}$ UASB reactor has confirmed that an internal $\mathrm{pH}$ of 6.9 and 60 to $80 \%$ COD removal are possible while feeding the reactor with settled not neutralized ( $\mathrm{pH}$ 4.3) PTA wastewater (Varela et al., 1998). In these conditions the loading rate was however limited to $2-3 \mathrm{~kg} \mathrm{COD} / \mathrm{m}^{3}$.d. During the same experiment, it was shown that TA suspended solids could be fed also to the system, considering $\mathrm{NaOH}$ addition to dissolve them.

\section{DESCRIPTION OF THE ANAEROBIC REACTOR}

The design of the anaerobic pre-treatment considered the technical and economical requirements of Temex (limited energy consumption, reduced sludge production, minimum COD removal of $60 \%$ and low investment cost) as well as the specific degradation kinetics and characteristics of this particular wastewater. These specifications were fulfilled with a design of an anaerobic reactor adapted to an existing pond.

The system is a three stage upflow anaerobic pond with a liquid depth from 6 to $4.5 \mathrm{~m}$ (total volume 20,808 $\mathrm{m}^{3}$ ) with the following characteristics: first stage volume $5,813 \mathrm{~m}^{3}$, second stage $8,719 \mathrm{~m}^{3}$, third stage UASB 
type $6,276 \mathrm{~m}^{3}$. The design flow is $230 \mathrm{~m}^{3} / \mathrm{h}$, with a COD concentration of $10,300 \mathrm{mg} / \mathrm{l}$. The system has an effluent recycling pump $\left(530 \mathrm{~m}^{3} / \mathrm{h}\right)$ in order to control upflow velocities and eventual acidification problems in the first two stages. A flare has been installed, and it is planned to use the biogas in the production plant. Figure 2 shows a diagram of the anaerobic system.

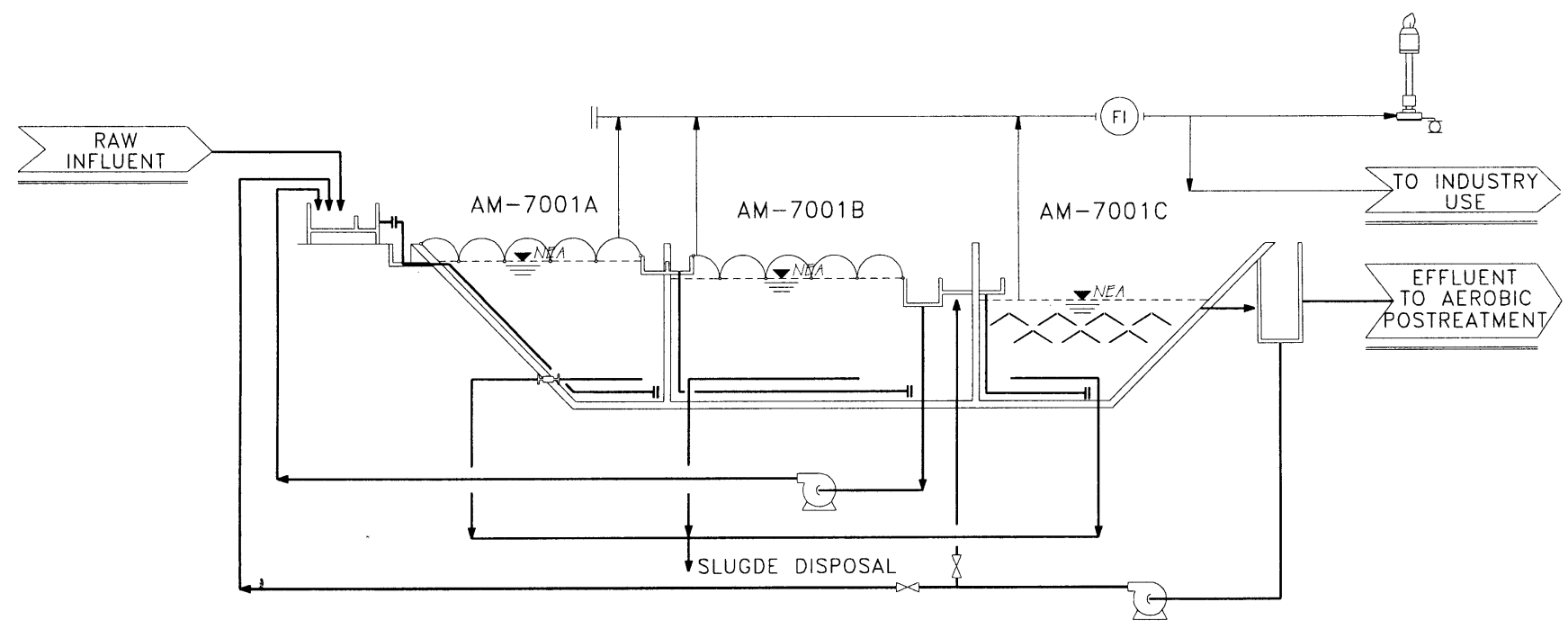

Figure 2. Schematic view of the anaerobic reactor with three stages in series adapted in one pond

The size of the pond made the installation of a conventional UASB type gas-liquid-solid separator difficult and expensive, so a solution with a plastic cover (Agrisilos, Italy) was adopted for the first two stages, while keeping the benefits of a bottom wastewater distribution. The third stage was designed as a conventional UASB reactor in order to have a clarified effluent, so the design suspended solids specification coming into the aerobic step could be met. This last stage provides additional removal capacity in case of organic shock loads to the first two anaerobic stages; it is in fact an anaerobic polishing element. The density of the bottom distribution system is 1 pipe per $6 \mathrm{~m}^{2}$ for the first stage, and 1 pipe per $4 \mathrm{~m}^{2}$ in the last two stages.

As the wastewater requires nutrients and some metals for a balanced biochemical reaction, a dosification system is placed at the headworks. In this installation, nitrogen (gaseous $\mathrm{NH}_{3}$ ), phosphorous $\left(\mathrm{H}_{3} \mathrm{PO}_{4}\right)$, sulfur and iron $\left(\mathrm{Fe}_{2}\left(\mathrm{SO}_{4}\right)\right)$, as well as nickel and molybdenum salts are added to the influent. The raw wastewater is received from the production plant at $40^{\circ} \mathrm{C}$ and at a $\mathrm{pH}$ of 4.5 . A pH control unit has been considered in case of need, mainly during start up. As mentioned, the anaerobic reaction degrades most of the acidic compounds present in the wastewater and produces bicarbonate alkalinity, which is returned to the influent by the recycling flow. As a result, in normal operating conditions, no exogenous neutralizing reagent should be needed.

\section{SELECTION AND PREPARATION OF SEED SLUDGE}

\section{Screening of different potential inocula}

Considering the anaerobic reactor size and hence the important amount of sludge required for inoculation, as well as the cost of granular sludge and the particular nature of the wastewater to be treated, 10 months before the estimated end of the construction period, 5 sludges from different sources available at Cosoleacaque Temex plant were evaluated for their ability to be used as inoculum (Hernández et al., 1997). Three of these sludges came from different storage pits of waste activated sludge, while the fourth was sampled from an anaerobic sludge digestion pond. The fifth sludge corresponded to fresh activated sludge from one of the aeration tanks. 
All the sludges were able to degrade anaerobically 46 to $88 \%$ of the COD of a settled and neutralized sample of Temex wastewater. COD degradation was even higher (64 to 100\%) when estimated from the produced methane. The digested and fresh activated sludge showed the best COD removals (86 and 96\% respectively, based on methane). As observed previously, a biphasic methane production was obtained. Contrarily to the other sludges which started producing $\mathrm{CH}_{4}$ almost instantaneously upon being in contact with the wastewater, the activated sludge presented a lag phase of around 10 days. However, the degradation activities of the sludges were rather low. For instance, the activity of the digested sludge, which is representative of the others, was limited to $93 \mathrm{mg} \mathrm{COD} / \mathrm{g}$ VSS.day for the first methane production phase (degradation of AA and BA) and $23 \mathrm{mg} / \mathrm{g}$ VSS.day for the second one (degradation of the aromatic compounds). Fresh activated sludge roughly carried half the activity of the digested one on AA and BA and $80 \%$ for the other compounds. Based on these values, and depending of the sludge, an amount of 56 to 201 tons of VSS would be necessary in order to start-up the industrial unit with a COD removal capacity of at least 5 to 10 tons per day.

\section{Activated sludge conditioning}

The waste activated sludge from the different pits being difficult to mobilize and the amount of digested sludge being rather limited, 8 months before the reactor start up, it was decided to mainly use activated sludge as inoculum and so the purge of the secondary settlers was recovered to improve its physical characteristics and degradation activities. In order to perform this operation, an existing pond with $12,000 \mathrm{~m}^{3}$ capacity and four mixers was put out of operation. To this pond, aerobic waste sludge was pumped, adding some macronutrients and a slow mixing. After two months of sludge accumulation, a batch feeding was started, with daily $\mathrm{pH}$ monitoring, kept at 6.5 minimum. Two months later, the accumulated sludge was removing roughly 2 to 3 tons COD/d, while maintaining in the pond a soluble COD concentration of 3,000 $\mathrm{mg} / \mathrm{L}$. The sludge with a concentration of 15 to $20 \mathrm{~g}$ TSS/L (60\% VSS) presented already improved settling properties (SVI of $108 \mathrm{~mL} / \mathrm{g} \mathrm{TSS}$ ) and activities (76.6 $\mathrm{mg}$ COD/g VSS.d). The sludge was however flocculent, $98 \%$ of its TSS corresponding to particles smaller than $0.23 \mathrm{~mm}$. The accumulation and acclimation processes were extended for eight months before the industrial unit was seeded. At this moment, the organic load being removed by the accumulated sludge was 4-6 tons COD/day, with a small sludge fraction with clear granular characteristics.

\section{REACTOR START-UP}

In August 1998, the adapted biomass was pumped from the sludge pond to the anaerobic reactor, at that moment without the plastic cover. The reactor was filled at approximately two thirds of its volume, with a sludge bed height of $0.5 \mathrm{~m}$. The first and second stages were filled up with raw wastewater, added at a slow rate, in order to be able to start the recycling pump from the effluent of the second stage to the influent of the first one.

At that moment, continuous feeding of wastewater, supplemented with nitrogen and phosphorous, began with a limited flow $\left(25 \mathrm{~m}^{3} / \mathrm{h}\right)$. The $\mathrm{pH}$ was not controlled, but it was monitored in order to keep it slightly below 7 .

Under these conditions, the system was able to remove 1 ton COD/d. The flow and the organic load fed to the reactor has been increased continuously since the inoculation, as can be seen in Figure 3. From June 99, $\mathrm{NaOH}$ addition $(50 \mathrm{~kg} /$ ton COD fed) has been adopted, in order to reach the design conditions more rapidly, keeping the effluent $\mathrm{pH}$ at 6.7, minimum allowed value. At August 99, the influent flow was $121 \mathrm{~m}^{3} / \mathrm{h}(2,900$ $\mathrm{m}^{3} / \mathrm{d}$ ), the organic load 17 tons COD/d, with a removal efficiency of $47 \%$. These figures indicate that at that moment, the reactor was treating $53 \%$ of the design flow and $30 \%$ of the design load. The reactor has shown an expected performance, considering the low initial degradation activity of the seed sludge and the slow growth rate of the anaerobic biomass. 

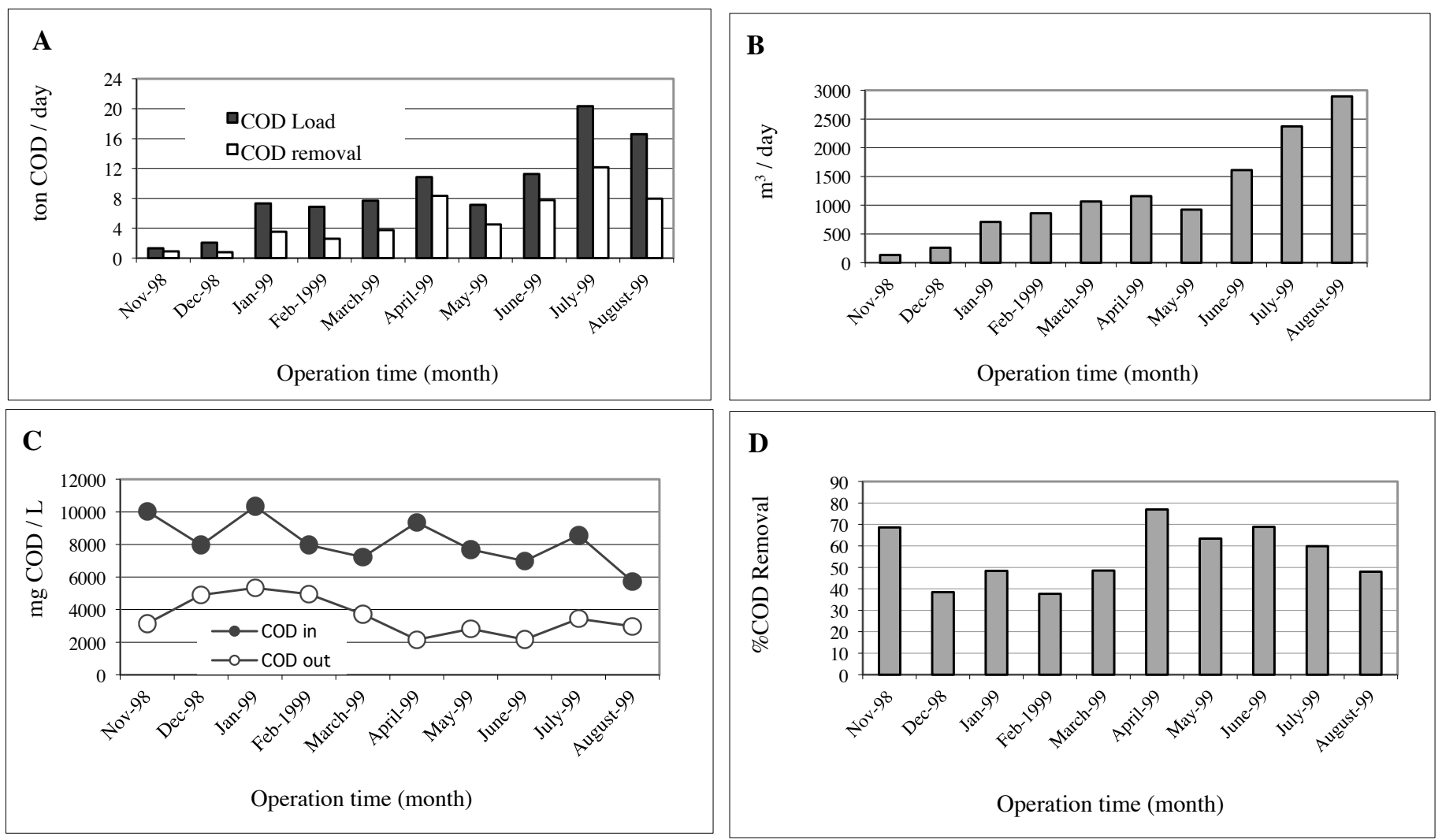

Figure 3 Evolution of the feeding conditions and reactor performances during the start-up (A: COD load; B: hydraulic load; C: influent and effluent COD; D: COD removal)

\section{CONCLUSIONS}

The design and construction of an anaerobic reactor with 3 stages in series through the adaptation of an existing pond, resulted in a sound solution to the petrochemical company. During the start-up period, the anaerobic system has presented the expected performance and the advantages of the anaerobic pre-treatment have been shown clearly in practice.

The steps taken in order to prepare a reasonable amount of inoculum from the waste activated sludge produced on site, led to good seeding material with reduced cost.

\section{ACKNOWLEDGEMENTS}

Half of the investment necessary for the construction of Temex anaerobic digester at Cosoleacaque was provided as a risk capital loan by Fidetec, a branch of Conacyt (National Science and Technology Council of Mexico). The authors thank Robbert Kleerebezem for constant fruitful discussions as well as Jean Pierre Guyot and Oscar Monroy for their decisive participation at the origin of this project, early in 1988.

\section{REFERENCES}

Bemis A. G., Dindorf J. A., Horwood B., Samans C. (1982). Phthalic acids and other benzene polycarboxylic acids. In: Kirk Othmer Encyclopedia of Chemical Technology, H. F. Mark, D. F. Othmer, C. G. Overberg, G. T. Seaborg, M. Grayson and D. Eckroth (eds)., vol 17, $3^{\text {rd }}$ edn, John Wiley and Sons, New York, USA, pp. 732-777. 
Cheng S. S., Ho C. Y. and Wu J. H. (1997). Pilot study of UASB process treating PTA manufacturing wastewater. Wat. Sci. Tech., 36(6-7), 73-82.

Dean J. A. (1992). Lange's Handbook of Chemistry. $14^{\text {th }}$ Ed., McGraw-Hill, Inc., New York, USA.

Fajardo C., Guyot J. P., Macarie H. and Monroy O. (1997). Inhibition of anaerobic digestion by terephthalic acid and by products. Wat. Sci. Tech., 36(6-7), 83-90.

Guyot J. P., Macarie H. and Noyola A. (1990). Anaerobic digestion of a petrochemical wastewater using the UASB process. Appl. Biochem. Biotechnol., 24/25, 579-589.

Hernández G., Laguna A. and Macarie H. (1997). Determination of the characteristics of different sludges available at Tereftalatos Mexicanos S. A. for inoculating the anaerobic digester. Report, 20/11/1997 elaborated by IRD/UAM-I for Temex, Cosoleacaque, Mexico, 24 pages (in Spanish).

Kleerebezem R., Hulshoff Pol L. W. and Lettinga G. (1999a). Anaerobic degradation of phthalate isomers by methanogenic consortia. Appl. Environ. Microbiol., 65, 1152-1160.

Kleerebezem R., Hulshoff Pol L. W. and Lettinga G. (1999b). The role of benzoate in anaerobic degradation of terephthalate. Appl. Environ. Microbiol., 65, 1161-1167.

Kleerebezem R., Ivalo M., Hulshoff Pol L. W. and Lettinga G. (1999c). High rate treatment of terephthalate in anaerobic hybrid reactor. Biotechnol. Prog., 15(3), 347-357.

Kleerebezem R., Moortier J., Hulshoff Pol L. W. and Lettinga G. (1997). Anaerobic pretreatment of petrochemical effluents : terephthalic acid wastewater, Wat. Sci. Tech., 36(2-3), 237-248.

Koster I. W. (1986). Methane production from acidic waste streams without addition of neutralizing chemicals. Environ. Technol. Lett., 7, 637-642.

Lau C. M. (1978). Staging aeration for high efficiency treatment of aromatic acids plant wastewater. In : Proc. $32^{\text {nd }}$ Ind. Waste Conf., Purdue University, Ann Arbor Science, Ann Arbor, USA, pp. 63-74.

Li Y. Y., Fang H. H. P., Chen T. and Chui H. K. (1995). UASB treatment of wastewater containing concentrated benzoate. J. Environ. Eng., 121(10), 748-751.

Macarie H. (2000). Overview on the application of anaerobic treatment to chemical and petrochemical wastewaters. Wat. Sci. Tech. 42(5-6), 201-213. (this issue)

Macarie H. and Guyot J. P. (1992). Inhibition of the methanogenic fermentation of p-toluic acid (4-methylbenzoic acid) by acetate. Appl. Microbiol. Biotechnol., 38, 398-402.

Macarie H. and Guyot J. P. (1995). Use of ferrous sulphate to reduce the redox potential and allow the start-up of UASB reactors treating slowly biodegradable compounds : application to a wastewater containing 4-methylbenzoic acid. Environ. Technol., 16, 1185-1192.

Macarie H., Noyola A. and Guyot J. P. (1992). Anaerobic treatment of a petrochemical wastewater from a terephthalic acid plant. Wat. Sci. Tech., 25(7), 223-235

Noyola A., Macarie H. and Guyot J. P. (1990). Treatment of terephthalic plant wastewater with an anaerobic fixed film reactor. Environ. Technol., 11, 239-248.

Page I. C., Wilson D. R., Cocci A. A., Landine R. C. (1998). Anaerobic hybrid treatment of terephthalic acid wastewater. In : Proc. $71^{\text {st }}$ Annual Water Environment Federation Conf., Orlando, Florida, USA, October 3-7, 1998, vol 3, pp. $575-586$.

Pereboom J. H. F., De Man G. and Su I. T. (1994). Start-up of full scale UASB-reactor for the treatment of terephthalic acid wastewater. In : Poster Papers, VII Int. Conf. Anaerobic Digestion, 23-27 January 1994, Cape Town, South Africa, pp. 307312.

Shelley S. (1991). And the winner is...Amoco Chemical, Chem. Eng., 98(12), 90-93.

Varela F., Macarie H., Marcelo R., Ramirez G., González F. J., Pérez A. (1998). Acidity, biodegradability and solids limitations in an anaerobic reactor fed with aromatic acids as COD source. In : Proc. V Latin-american Workshop-Seminar Wastewater Anaerobic Treatment, 27-30 October 1998, Viña del Mar, Chile, 13 pages.

Young J. C. (1997). Anaerobic treatability of phthalic acid production wastewaters. In : Proc. $8^{\text {th }}$ Int. Conf. Anaerobic Digestion, 25-29 May 1997, Sendai, Japan, vol 1, pp. 380-387. 